\title{
Urgences
}

\section{Denuis Saint-Yves, Parler ne s'entend pas, Trois-Rivières, Écrits des Forges, 1981.}

\section{Jean Cossette}

Numéro 6, 4e trimestre 1982

URI : https://id.erudit.org/iderudit/025095ar

DOI : https://doi.org/10.7202/025095ar

Aller au sommaire du numéro

Éditeur(s)

Urgences

ISSN

0226-9554 (imprimé)

1927-3924 (numérique)

Découvrir la revue

Citer ce compte rendu

Cossette, J. (1982). Compte rendu de [Denuis Saint-Yves, Parler ne s'entend pas,

Trois-Rivières, Écrits des Forges, 1981.] Urgences, (6), 87-90.

https://doi.org/10.7202/025095ar

Ce document est protégé par la loi sur le droit d'auteur. L’utilisation des services d’Érudit (y compris la reproduction) est assujettie à sa politique d'utilisation que vous pouvez consulter en ligne.

https://apropos.erudit.org/fr/usagers/politique-dutilisation/
Cet article est diffusé et préservé par Érudit.

Érudit est un consortium interuniversitaire sans but lucratif composé de l’Université de Montréal, l'Université Laval et l'Université du Québec à Montréal. Il a pour mission la promotion et la valorisation de la recherche. https://www.erudit.org/fr/ 


\section{PARUTION COMMENTÉES}

PARLER NE S'ENTEND PAS, Denuis Saint-Yves. Écrits des Forges, Trois-Rivières, 1981.

"inachevé bien plus que fugitif fragmentaire le référent (se) frais (ce) légèrement réduit

d'anciennes rapidités linéaires à s'esclaffer"

Ces quelques lignes tirées du poème "MAXI", en disent long sur une certaine perception que pourrait avoir le prochain lecteur qui se penchera sur PARLER NE S'ENTEND PAS. En effet, du moins dans la première partie du recueil, a-t-on cette impression de vides et de pleins. L'auteur, à force de ne garder que l'essentiel du langage (comprendre ici son langage), nous transporte bon gré mal gré sur un radeau où la sémantique fait plutôt office de naufragé que de boussole. C'est ainsi que Denuis Saint-Yves semble être le seul à pouvoir nous indiquer la direction, la bonne, qui nous mènerait à destination. Si toutefois il en est une...

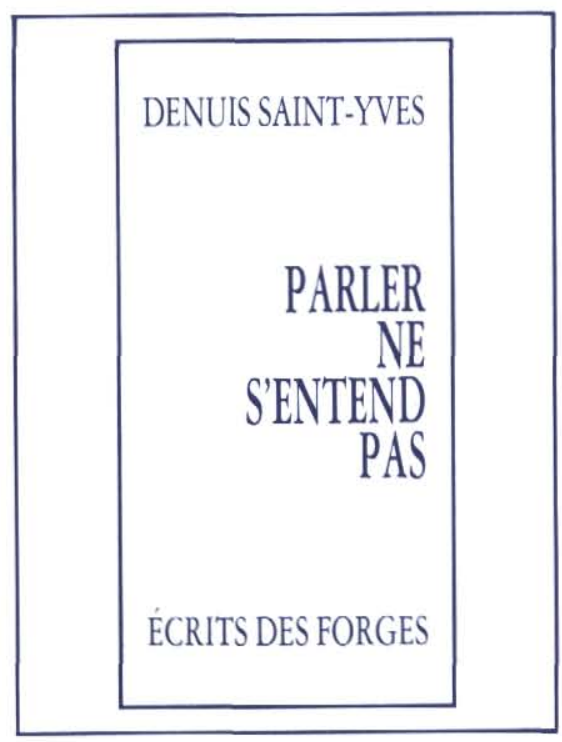


A chacun des textes correspond une borne, en ce sens que le lecteur pourra trouver dans les pages de gauche, un message adressé à "Gatien". Donc il sera possible de tirer, à même ces bouées, des phares qui jetteraient un peu de lumière sur le but ultime du poète. Ainsi, après avoir tenté de déchiffrer certains textes à l'allure de sémaphores, peut-on se laisser couler paisiblement dans ces îlots-manuscrits, style "Ce langage comme une fissure dans l'étrangeté de votre sort, violent, esseulé, se heurtant à l'entendement. Langage qui tient plus du sang que de la parole". Ces repères sont à n'en point douter une consolation. Une consolation de ne pouvoir saisir Saint-Yves que par bribes. Veut-il brouiller ses traces, comme le disait Montherlant des écrivains en général? À tout passer au tamis et à disséquer ainsi le langage, ce poète a raison de dire: “... j'ai l'impression douloureuse d'être resté dans la marge du dire, du vouloir dire". Même si la deuxième partie nous révèle davantage de la profondeur et de la conscience acerbe de Saint-Yves, elle reste quand même difficile à percer et l'absence de ponctuation laisse le lecteur libre de commencer ses phrases là où il le veut bien. Curieusement, en première partie, la ponctuation se fait omniprésente, voire envahissante.

Quoi qu'il en soit, et comme un révélation soudaine, les écrits intitulés "TEXTE" et "POĖME" nous livrent beaucoup plus qu'une brèche vivifiante sur l'oeuvre... une clé! une véritable clé serait le mot. Ainsi, après avoir glissé" ... le lecteur y joue de malchance et la rage le gagne car les mots du poème ne sont pas à sa convenance et cette page il la déchirerait volontiers ("BREF"), Denuis Saint-Yves nous réconcilie-t-il avec son univers où les signifiants-signifiés se renvoient la balle, dans les champs métaphoriques du silence verbal.

A la difficulté de lire, i.e. décoder, le lecteur penché sur cette page sans fin tellement elle est dense, riche et sans frontière vraiment, le lecteur dis-je, s'abîmera malheureusement les yeux sur des caractères minuscules, mal aérés et qui n'ajouteront qu'impatience à cette recherche ardue, à cette réflexion hors du temps et de l'espace. PARLER NE S'ENTEND PAS est un livre à digérer lentement, très lentement, quelque part dans le cosmos. 
MILLE CRIS DANS LA NUIT, Francine Carrier, 154 pages plus photos. Éditions Pierre David, Luceville, 1982.

20 mai $1914-$ Winnipeg

"Le vieux fauteuil de la loge craque sous le poids d'Hilda qui s'agite et remue sans cesse, alourdie par un profond sommeil."

Dans cette ère avide de romantisme alors que I'opinion publique, aidée par la traduction française LE NAUVRAGE DE L'EMPRESS, confiée au rimouskois Serge Proulx, se repenche sur les désastres maritimes, Francine Carrier, elle, choisit d'adopter une forme typiquement romanesque pour traiter du même sujet.

Spatialement, son livre ne néglige rien. Nous suivons les étapes du voyage comme l'embarquement des personnages, de si infime condition soient-ils. Duluth. Détroit. Montréal. Québec. Et puis s'engage la vie à bord. Routinière. Paisible. Jusqu'au drame.

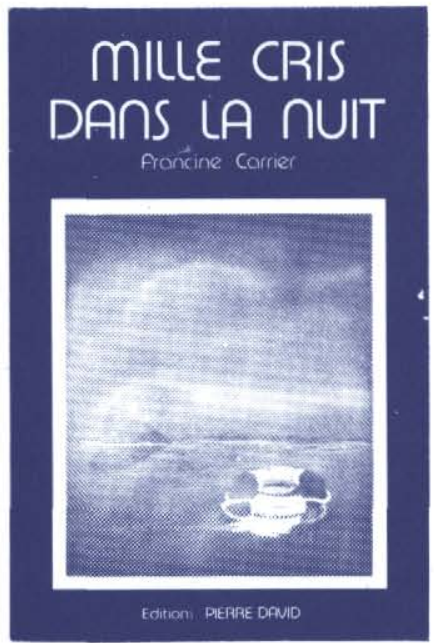

Hilda, c'est la dame de compagnie de la femme du capitaine. Tigresse sur les bords. Qui n'a pu être suivie de son ami manoeuvre et qui tarde d'arriver en Angleterre pour l'attendre. Rêve banal d'un petit peuple. 
Ce que Francine Carrier a cherché, dans son roman, c'est d'abord à s'identifier aux personnages obscurs, à ceux dont l'actualité de l'époque n'a pas parlé. Elle a pris sur elle d'inventer et de préciser leurs émotions.

Documentée, l'auteure cache ses connaissances au profit d'une intrigue qu'elle tend à rendre la plus sympathique possible. Dommage. Car les détails historiques, existants, se fondent dans un langage dont on retient surtout la facilité d'écriture et les multiples clichés qu'on ne peut taire.

"Mille cris dans la nuit", ces cris de désespoir poussés par les rescapés et par ceux qui ont péri dans le naufrage de l'Empress, si détaillés soient-ils, convainquent mal. Auréolés d'une vision voulue trop humaine.

Ce n'est pas l'intention, c'est donc le traitement qui fait de ce livre, qui se lit bien, une tentative discutable. Peut-être parce que tout phénomène historique, à moins d'une habileté sans borne, ne se prête pas à une interprétation romancée...

Hélène Chassé

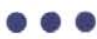

DES IRES RÉELLES, poèmes de Ghislain Bérubé, 96 pages. IIlustrations de Dorys Tremblay. Éditions Passages, Rimouski, 1982.

Ce premier ouvrage de Ghislain Bérubé est divisé en cinq parties (Des ires d'en dedans, Des ires d'en dehors, Désirs, Ires funambulesques et Désirs voyageurs) mais il conserve tout au long une unité de ton que peu de nouveaux poètes possèdent en propre.

Identifié au funambule, le poète (comme d'ailleurs le commun des mortels dont il est) aura traversé sur la corde raide, et avec une certaine prestance malgré les pièges de la réalité et ceux de la littérature, ses propres colères intérieures provoquées par un environnement humain qu'il aura perçu comme factice: "être en 